\title{
A Skeptical Perspective on High-Flow Nasal Cannula in the Treatment of Acute Hypoxemic Respiratory Failure
}

The delivery of oxygen, whether as treatment for hypoxemia or supportive adjunct in shock or surgery, is a mainstay of modern medical therapy, yet conventional oxygen therapy, delivered either by nasal cannula or face mask, remains limited by the high oxygen delivery demand of the acute and critically ill patient. By employing a tight fitting mask or mask-like interface, noninvasive ventilation (NIV) overcomes these limitations and has been shown to improve outcomes in acute-on-chronic respiratory failure ${ }^{1}$ or cardiogenic pulmonary edema (congestive heart failure), ${ }^{2}$ albeit at the expense of comfort and patient compliance.

Enter the high-flow nasal cannula (HFNC), a device not only capable of delivering high flow (up to $60 \mathrm{~L} / \mathrm{min}$ ) of heated and humidified gas through wide-bore nasal prongs, but also proficient at counteracting the limitations of conventional oxygen delivery devices. ${ }^{3} \mathrm{~A}$ touted advantage is comfort, probably a result of the combination of the physical characteristics of the device, and a reduction in desiccation commonly associated with the cold, dry air flow of conventional oxygen therapy. Nonetheless, the evidence for the use of HFNC to date has been conflicting and has been derived from highly screened and specific patient populations, limiting the ability to provide generalized treatment recommendations for its use by the acute care respiratory therapist or practitioner in the patient with hypoxemic failure (Table 1).

Although it remains the growing perception that HFNC represents a reasonable therapeutic alternative for situations where conventional oxygen delivery and NIV fail to provide adequate symptom relief of acute-on-chronic respiratory failure, ${ }^{4,5}$ high quality clinical investigations of the efficacy of HFNC in the critical care arena remain lacking. A recent multi-center, randomized, controlled trial by Frat et $\mathrm{al}^{6}$ explored a more prominent role for HFNC as first-line therapy in acute, non-hypercapnic hypoxemia. Although no difference in the primary end point of intu-

\footnotetext{
The authors have disclosed no conflicts of interest.
}

Correspondence: Richard A Oeckler MD PhD, Division of Pulmonary and Critical Care Medicine, Mayo Clinic, 200 First Street SW, Rochester, MN 55905. E-mail: oeckler.richard@mayo.edu.

DOI: $10.4187 /$ respcare. 04473 bation rate was found, subjects receiving HFNC experienced more ventilator-free days and a lower mortality when compared with subjects that received conventional oxygen therapy or NIV. However, the limited patient population, comparatively disparate mortality in the shock subgroups, and the non-protective ventilation strategy (average tidal volume $\left[\mathrm{V}_{\mathrm{T}}\right]$ in excess of $9 \mathrm{~mL} / \mathrm{kg}$ ) in the NIV group preclude a definitive conclusion from these results.

See the Original Study on Page 1369, 1377,

$$
\text { 1383, 1390, AND } 1397
$$

In this issue of Respiratory CARE, 5 original research articles by Nagata et al, ${ }^{7}$ Gaunt et al, ${ }^{8}$ Rittayamai et al, ${ }^{9}$ Vargas et al, ${ }^{10}$ and Parke et al ${ }^{11}$ explore aspects of HFNC ranging from the physiologic basis for its use to the comparative risks, benefits, and clinical efficacy of conventional oxygen therapy, NIV, and HFNC in the acute care setting. In the end, and in the context of conflicting end points, such as length of stay, ventilator-free days, and mortality, prudence suggests a skeptical interpretation of appropriate use for HFNC in patients experiencing acute hypoxemic, non-hypercapnic respiratory failure.

\section{In Support of HFNC for Acute Respiratory Failure}

Respiratory care providers are often challenged by flow and $\mathrm{F}_{\mathrm{IO}_{2}}$ demand matching, intolerance of dry inspired gas and its effect upon airway secretions, and claustrophobia while treating acute respiratory failure. HFNC addresses these shortcomings through delivery of high flow (30$60 \mathrm{~L} / \mathrm{min}$ ) heated and humidified gas at a constant $\mathrm{F}_{\mathrm{IO}_{2}}$ via a wide-bore nasal interface. ${ }^{3}$ Its comfort has been wellestablished, including in the current study of emergency department subjects by Rittayamai et al, ${ }^{9}$ and correlates with patient compliance.

The perception of comfort is complex, probably a result of interface characteristics combined with real and perceived physiologic variables such as anxiety level, breathing frequency, and work of breathing. Several theories as to how HFNC may alter respiratory mechanics include enhanced washout of dead space with increased carbon dioxide removal, improved humidification and its effect 
Table 1. Risks and Benefits of High-Flow Nasal Cannula

\begin{tabular}{l}
\hline \hline Benefits \\
Comfort/improved compliance \\
Virtually unlimited flow and $\mathrm{F}_{\mathrm{IO}_{2}}$ demand matching \\
Decreased inspiratory effort \\
Mild PEEP generation \\
Humidification, secretion improvement \\
Dead space washout $\left(\mathrm{CO}_{2}\right.$ removal) \\
Limitations/Risks \\
Inability to measure or restrict $\mathrm{V}_{\mathrm{T}}$ \\
Mobility (limited ambulation and disposition) \\
Leak mitigation/compensation \\
Nasopharyngeal airway pressure and PEEP warrant more \\
exploration \\
Potential for delayed intubation (increased mortality) \\
\hline
\end{tabular}

on airway secretions, and the generation of PEEP, a beneficial by-product of high flow delivery. ${ }^{3}$ Two small studies in this issue from Parke et al ${ }^{11}$ and Vargas et al. ${ }^{10}$ used complementary experimental approaches to demonstrate physiologic changes during HFNC use that could presumably improve oxygenation as well as symptoms typically associated with respiratory distress. Both studies reported a rapid, significant decrease in breathing frequency after the initiation of HFNC. Moreover, through the use esophageal manometry, Vargas et $\mathrm{al}^{10}$ measured a reduction in pressure time product. Parke et $\mathrm{al}^{12}$ had previously described a linear correlation between flow and airway pressure in HFNC up to the currently accepted maximum rate of $60 \mathrm{~L} / \mathrm{min}$. Here, ${ }^{11}$ they increased flow up to as much as $100 \mathrm{~L} / \mathrm{min}$ in healthy volunteers and quantified the correlation between flow rate and nasopharyngeal PEEP at about $1 \mathrm{~cm} \mathrm{H}_{2} \mathrm{O}$ nasopharyngeal PEEP increment for each $10 \mathrm{~L} /$ min of flow, up to a maximum of $8-12 \mathrm{~cm} \mathrm{H}_{2} \mathrm{O}$ at $100 \mathrm{~L} /$ $\min$.

It remains unknown whether the commonly reported nasopharyngeal measurements correlate with similar increases where it really matters for the acutely hypoxemic patient: PEEP at the level of the alveolus. Underscoring this point, we note that change in end-expiratory lung impedance (and thus end-expiratory lung volume) was widely variable, suggesting either a limitation of technique or that the relationship between flow and end-expiratory lung volume may be more complicated then assumed. The latter possibility appears to be supported by the analysis of the $\mathrm{P}_{\mathrm{aO}} / \mathrm{F}_{\mathrm{IO}_{2}}$ data from Vargas et al. ${ }^{10}$ Applying the estimate $\left(10 \mathrm{~L} / \mathrm{min}\right.$ flow $\left.=1.2 \mathrm{~cm} \mathrm{H}_{2} \mathrm{O}\right)$ of Parke et al ${ }^{11}$ to the subjects in Vargas' study with flow fixed at $60 \mathrm{~L} / \mathrm{min}$ in all subjects, one would expect an airway pressure of between 5 and $7 \mathrm{~cm} \mathrm{H}_{2} \mathrm{O}$. If this were to correlate with PEEP at the alveolus, as has been implied in previous studies, it would not be unreasonable, using a conservative interpretation of such estimates, to expect a comparable improvement in oxygenation in both the $60 \mathrm{~L} / \mathrm{min}$ HFNC group and the NIV group receiving $5 \mathrm{~cm} \mathrm{H}_{2} \mathrm{O}$ CPAP. Yet, HFNC produced only a slight but significant improvement in $\mathrm{P}_{\mathrm{aO}_{2}} / \mathrm{F}_{\mathrm{IO}_{2}}$ versus conventional oxygen therapy $\left(\mathrm{P}_{\mathrm{aO}_{2}} / \mathrm{F}_{\mathrm{IO}_{2}}=\right.$ 167 vs 156), and despite attempts by Vargas et al ${ }^{10}$ to compensate or correct for several common pitfalls of HFNC (highest possible flow and ensuring that the patient's mouth remained closed), they found that it fell far short of the increased oxygenation under $\mathrm{NIV}\left(5 \mathrm{~cm} \mathrm{H}_{2} \mathrm{O}\right.$ CPAP; $\mathrm{P}_{\mathrm{aO}_{2}} / \mathrm{F}_{\mathrm{IO}_{2}}=167$ vs 228). Although the relationship between HFNC and PEEP remains poorly characterized, the potential for HFNC at higher flows $(50-100 \mathrm{~L} / \mathrm{min})$ to generate levels of PEEP comparable with NIV or invasive mechanical ventilation while maintaining comfort and facilitating compliance remains highly attractive. However, until subsequent research quantifies a positive relationship between HFNC and alveolar PEEP generation, making broad generalizations appears to be more of a leap of faith than an evidence-based conclusion.

\section{Cautions and Limitations in the Use of HFNC}

Despite promising, hypothesis-generating findings, the current studies' limitations preclude the widespread adoption of HFNC in the acutely hypoxemic patient, primarily because traditional HFNC study populations are limited in duration or scope or use data from young healthy subjects to support sweeping inferences of applicability and treatment in older, critically ill patients with multiple comorbidities. Although highly focused studies may yield practical applications (eg, the use of HFNC in postextubation cardiovascular surgery patients), ${ }^{13}$ caution is recommended when extrapolating limited data sets to other acutely hypoxemic patients. Unfortunately, it is exactly because such limited data exist for HFNC that the temptation exists to interpret and translate findings from one group to another, leading to conflicting results (breathing frequency goes up, down, or stays the same; work of breathing is increased, decreased, or unchanged) or miscomparison between conventional oxygen therapy, NIV, and HFNC. However, it would seem that additional data from a spectrum of highly relevant, critically ill patient populations (smokers, COPD, pulmonary fibrosis, and the obese) with varying severities of illness may be a prerequisite for generalizing the efficacy of HFNC.

The safe implementation of HFNC, like any modality, requires the a priori establishment of clear and objective abandonment criteria and realistic patient goals. Failure may be the result of a combination of factors, including delay in the timely initiation of support, an inappropriate level of support rendered, failure to adjust the level of support as the clinical course unfolds, or continuing the support for too long despite deterioration. The latter may be due to a lack of predefined discontinuation criteria, 
distraction and/or missed cues, inexperience with the device and its use, or a desire to avoid escalation due to patient or provider bias. The current studies by Nagata et al, ${ }^{7}$ Gaunt et al, ${ }^{8}$ Rittayamai et al, ${ }^{9}$ and Vargas et al. ${ }^{10}$ failed to define such abandonment criteria, and in particular, Rittayamai et $\mathrm{al}^{9}$ acknowledge several such limitations of their study. First, a median 1.5 h elapsed between recognition and implementation of HFNC or conventional oxygen therapy. The energy reserves expended while attempting to compensate for their respiratory status during this time probably set these subjects up for eventual failure. Second, conventional oxygen delivery was limited to a median $8.5 \pm 3.4 \mathrm{~L} / \mathrm{min}$ and $5.6 \pm 3.0 \mathrm{~L} / \mathrm{min}$ in the non-rebreathing mask group. In the context of acuteon-chronic respiratory failure, such levels of support were probably inadequate.

An oft-raised concern regarding HFNC is the potential for delay in escalation of care in the decompensating patient. Failure of HFNC therapy may delay intubation and increase mortality. ${ }^{14}$ Missed cues and failure to recognize deterioration play an important role in the management of hypoxia in the postextubation patient as well. In the ideal world, all patients would extubate early and never fail; realistically, MacIntyre et al have suggested that $5-15 \%$ represents an acceptable re-intubation rate. ${ }^{15}$ In this context, the re-intubation rate of $20 \%$ reported by Gaunt et al ${ }^{8}$ may imply that: (1) subjects were extubated prematurely, (2) the health-care team failed to diagnose a change in subject condition or clinical status, and/or (3) subjects did not receive appropriate postextubation bronchial hygiene therapy, supplemental oxygen delivery, or alternative noninvasive support devices as a means to prevent or mitigate the occurrence or likelihood that the patient would require re-intubation.

Several key limitations to HFNC include issues surrounding leak mitigation (mouth closed, nasal breathing), ease of patient mobility (gas consumption rate with high flow nasal cannulas), and the inability to restrict $V_{T}$ to the generally accepted protective range $(<6-8 \mathrm{~mL} / \mathrm{kg}$ ideal body weight). We would be remiss not to address the importance of $\mathrm{V}_{\mathrm{T}}$ in HFNC vis a vis ventilator-induced lung injury. Based on significant and thorough investigation, a generally accepted lung-protective ventilation strategy has been established for invasive ventilation, yet no such recommendations appear for the NIV patient, and as health-care professionals, we often tolerate $\mathrm{V}_{\mathrm{T}}$ on NIV (and probably continuous oxygen therapy and HFNC) that would never be tolerated as safe with invasive mechanical ventilation. Are the implications the same? If so, although the data of Vargas et al ${ }^{10}$ suggest a beneficial role for HFNC in the reduction of breathing frequency, drive, and pressure time product, its applicability without complex monitoring of $\mathrm{V}_{\mathrm{T}}$ to guide adjustment may lead to missed cues and prolongation of eventual failure.

\section{An Approach to HFNC in Acute Respiratory Failure}

Although we have highlighted several limitations and gaps in the current knowledge base that preclude a generalized adoption of HFNC in all patients with acute respiratory failure, we believe that there are several scenarios that warrant a consideration of HFNC at this time. In select medical and postoperative patients, where data indicate that early mobilization and extubation clearly improves outcome, there appears to be a role for the use of HFNC in patients with a postextubation $\mathrm{P}_{\mathrm{aO}_{2}} / \mathrm{F}_{\mathrm{IO}_{2}}<300$ to prevent re-intubation. Similarly, we recommend a cautious trial of HFNC in patients with increased inspiratory effort in which failure and the need for intubation may be avoided simply by a reduction in breathing frequency and drive. In palliative or hospice situations primarily driven by comfort and the desire to avoid intubation, HFNC is an excellent alternative to conventional oxygen therapy or NIV.

When compared with NIV, the evidence is less robust for the use of HFNC as first-line therapy in the patient presenting in acute respiratory failure. Clearly certain patients in this category may benefit from HFNC, and if considered, it should utilize an approach similar to that of NIV in such situations: a short trial (1-4 h), closely monitored for decompensation with clearly delineated abandonment criteria and a low threshold for escalation of support, as necessary. A caveat remains for the patient with acute hypercapnic failure, where dead space washout and direct correlation between flow and airway pressure are especially enticing, yet the data are limited and inconclusive with regard to any role for HFNC in these patients at this time. Certainly, the physiologic studies in this issue of RESPIRATORY CARE add to the growing literature suggesting HFNC as a potential alternative to conventional oxygen therapy and NIV in select patients with acute respiratory failure; however, further large randomized clinical trials of diverse, acutely ill populations remain warranted.

Christopher D Roberts RRT
Department of Respiratory Care
Mayo Clinic
Rochester, Minnesota
Richard A Oeckler MD PhD
of Pulmonary and Critical Care
Department of Medicine
Mayo Clinic
Rochester, Minnesota

\section{REFERENCES}

1. Messika J, Ben Ahmed K, Gaudry S, Miguel-Montanes R, Rafat C, Sztrymf B, et al. Use of high-flow nasal cannula oxygen therapy in subjects with ARDS: a 1-year observational study. Respir Care 2015; 60(2):162-169. 


\section{EDITORIALS}

2. Cabrini L, Landoni G, Oriani A, Plumari VP, Nobile L, Greco M, et al. Noninvasive ventilation and survival in acute care settings: a comprehensive systematic review and metaanalysis of randomized controlled trials. Crit Care Med 2015;43(4):880-888.

3. Chanques G, Constantin JM, Sauter M, Jung B, Sebbane M, Verzilli $\mathrm{D}$, et al. Discomfort associated with underhumidified high-flow oxygen therapy in critically ill patients. Intensive Care Med 2009; 35(6):996-1003.

4. Boyer A, Vargas F, Delacre M, Saint-Léger M, Clouzeau B, Hilbert G, Gruson D. Prognostic impact of high-flow nasal cannula oxygen supply in an ICU patient with pulmonary fibrosis complicated by acute respiratory failure. Intensive Care Med 2011;37(3):558-559.

5. Sztrymf B, Messika J, Mayot T, Lenglet H, Dreyfuss D, Ricard JD. Impact of high-flow nasal cannula oxygen therapy on intensive care unit patients with acute respiratory failure: a prospective observational study. J Crit Care 2012;27(3):324.e9-13.

6. Frat JP, Thille AW, Mercat A, Girault C, Ragot S, Perbet S, et al. High-flow oxygen through nasal cannula in acute hypoxemic respiratory failure. N Engl J Med 2015;372(23):2185-2196.

7. Nagata K, Morimoto T, Fujimoto D, Otoshi T, Nakagawa A, Otsuka $\mathrm{K}$, et al. Efficacy of high-flow nasal cannula therapy in acute hypoxemic respiratory failure: decreased use of mechanical ventilation. Respir Care 2015;60(10):1390-1396.

8. Gaunt KA, Spilman SK, Halub ME, Jackson JA, Lamb KD, Sahr SM. High-flow nasal cannula in a mixed adult ICU. Respir Care 2015;60(10):1383-1389.
9. Rittayamai N, Tscheikuna J, Praphruetkit N, Kijpinyochai S. Use of high-flow nasal cannula for acute dyspnea and hypoxemia in the emergency department. Respir Care 2015;60(10):1377-1382.

10. Vargas F, Saint-Leger M, Boyer A, Bui NH, Hilbert G. Physiologic effects of high-flow nasal cannula oxygen in critical care subjects. Respir Care 2015;60(10):1369-1376.

11. Parke R, Bloch A, McGuinness S. Effect of very-high-flow nasal therapy on airway pressure and end-expiratory lung impedance in healthy volunteers. Respir Care 2015;60(10):1397-1403.

12. Parke RL, McGuinness SP, Eccleston ML. A preliminary randomized controlled trial to assess effectiveness of nasal high-flow oxygen in intensive care patients. Respir Care 2011;56(3):265-270.

13. Corley A, Caruana LR, Barnett AG, Tronstad O, Fraser JF. Oxygen delivery through high-flow nasal cannulae increase end-expiratory lung volume and reduce respiratory rate in post-cardiac surgical patients. Br J Anaesth 2011;107(6):998-1004.

14. Kang BJ, Koh Y, Lim CM, Huh JW, Baek S, Han M, et al. Failure of high-flow nasal cannula therapy may delay intubation and increase mortality. Intensive Care Med 2015;41(4):623-632.

15. MacIntyre NR, Cook DJ, Ely EW, Jr., Epstein SK, Fink JB, Heffner $\mathrm{JE}$, et al. Evidence-based guidelines for weaning and discontinuing ventilatory support: a collective task force facilitated by the American College of Chest Physicians; the American Association for Respiratory Care; and the American College of Critical Care Medicine. Chest 2001;120(6):375S-395S. 